\title{
A Conversation with Bernard de Massy
}

\author{
INTERVIEWER: LARA SZEWCZAK \\ Scientific Editor, Cell
}

Bernard de Massy is a Researcher at the Institute of Human Genetics of the National Center for Scientific Research in Montpellier, France.

Lara Szewczak: Your lab focuses on meiosis and the process of recombination. What got you into the field in the first place?

Dr. de Massy: My first interest was evolution, and then I got trained into DNA metabolism: DNA replication, DNA recombination. I realized that there was one area where I could really try to develop an understanding of the molecular mechanism, but with evolutionary implications: the process of recombination during meiosis. It's really a molecular machinery that has very long-term consequences on the transmission of genetic information, on genome diversity. That was really what made me choose this field.

Lara Szewczak: What was the question that you started with when you started working on meiosis?

Dr. de Massy: The first question...that was in budding yeast...was to characterize some specific sites of meiotic recombination in the yeast genome that were just discovered a few years before. I've been really continuing this trajectory from yeast, but now it's already 20 years. I shifted to mouse and ask similar question in mammals, in mouse meiosis.

Lara Szewczak: You've really focused on how the breaks form. Tell us a little about that.

Dr. de Massy: Seven years ago, we discovered a factorPRDM9 [PRD and RIZ homology DoMain containing protein 9] - and I think it's been a dream for me. In characterizing this protein and the molecular mechanism of breaks that are induced in meiosis, it unexpectedly turned out that it has enormous evolutionary implications. This protein works by specifying the sites in the genome where recombination takes place. It's amazing, because it really breaks some established concepts about the genetic map: the genetic linkages that were thought to be fixed and follow some rules according to, I don't know, gene functions, for instance. The way this gene works in mammals shows that the genetic map is actually incredibly plastic.

Lara Szewczak: How does it work?

Dr. de Massy: This protein in particular, it binds to DNA. It has some specific DNA binding recognition, but we've evaluated that it binds to maybe 10 to 15 thousand potential sites in the genome. Then it modifies the histones that are on the nucleosomes adjacent to its binding sites. So, it modifies the nucleosome, the histones, and then...we don't know very well, actually. We assume that it interacts with other proteins. There are some postulated interactions we are currently trying to validate to attract the protein that catalyzes the formation of double strand breaks and the catalytic activity. We know which protein encodes for the catalytic activity - it's SPO11 - but we don't know how these proteins get together. That's the part we don't know how it works.

Lara Szewczak: There doesn't seem to be any redundancy. When you don't have PRDM9, you aren't positioning the breaks. That seems really dangerous, when you think about the process of meiosis and the fact that you do want to be able to have this process happen and diversity get introduced. Was that surprising to you?

Dr. de Massy: Let me put it slightly differently. There is still a big surprise and still an unsolved paradox with this protein, but for a slightly different reason. This protein is found in many vertebrates. We are not exactly sure of the phylogeny, but it probably arose with the emergence of vertebrates or maybe earlier. But it has been lost, independently, in many vertebrate lineages. It has been lost in birds, in some mammals, in some fish, and those species without this PRDM9 protein do perfectly well. Recombination takes place at sites that are apparently accessible chromatin and maybe they have some modification in particular, but the pattern of recombination is completely different in mammals like humans, versus another mammal, like dogs - Canidae - where they don't have PRDM9. There are two alternative pathways; that's the way it looks. And PRDM9 is a very specific and unusual pathway because its activity destroys its own binding sites across generations. It's very puzzling: Why is PRDM9 doing this, whereas other species can do perfectly well without it? Is there an advantage for this specific function? What PRDM9 does is that it makes the position of recombination events dynamic...I mean dynamic during evolution, meaning that they change over time.

(C) 2017 de Massy. This article is distributed under the terms of the Creative Commons Attribution-NonCommercial License, which permits reuse and redistribution, except for commercial purposes, provided that the original author and source are credited. 
Lara Szewczak: So because it destroys its own sites, you can't then rebind.

Dr. de Massy: Exactly, and then there are new variants that probably come in that are selected and design for recombination to take place at different sites, whereas species that don't have PRDM9 have fixed and stable sites of recombination. That's very exciting for me. To really understand this molecule, we need to take into account its long-term evolutionary implications. I'm now constantly discussing and interacting with evolutionary biologists to try to appreciate this. That's a challenge.

Lara Szewczak: On the one hand, you're interacting with evolutionary biologists, on the other hand, you're trying to understand the molecular interactions that let you bridge from PRDM9 in specific binding sites to SPO11 that's actually doing the cleavage. What approaches are you taking to look at that?

Dr. de Massy: Biochemistry. It's not easy because of the cells that we are working on-mouse oocytes or mouse spermatocytes - but it's a completely different approach with a different experimental procedure. More and more, it's a biochemical approach.

Lara Szewczak: Are you bringing in other model organisms, or are you sticking with mouse, because of the concerns of differences of mechanism?

Dr. de Massy: That's an important point: whether the system we are using is the best one to answer the question. In this specific context, if we want to understand where and how PRDM9 works, I don't know which alternative I could take. There are other organisms where the molecular understanding of recombination is very well developed, like yeast, but yeast doesn't have PRDM9, so that's not an option. So, right now that's my choice and we have to continue and use this system if we want to progress.

Lara Szewczak: If those are the questions that you are thinking about now, what's just beyond reach? What questions do you want to be answering in 3 years?

Dr. de Massy: I'm interested in the molecular mechanism of meiosis, but not in all the detail. I don't think I will go into the deepest details of a particular molecular reaction. That's not my interest. I'm rather interested in how this event at the DNA level takes place in the context of the nucleus. Meiosis, and meiotic prophase in particular, is really fantastic. There are plenty of completely unsolved questions. Somehow, when the breaks are formed, they have to be repaired and interact with homologous sequences, which are present on the homologous chromosomes. There is, I think, a relatively black box about how broken DNA finds the homologous sequence. Nobody really knows how it works. Chromosomes have to find each other. The chromosomes have to move, and there already is some data on that movement. To answer your question, the idea would be to link this molecular event with chromosome movement and dynamics, and ideally to follow the movement live in the nucleus.

Lara Szewczak: To get to the point where you can answers those questions, what are you gearing up to do in the lab?

Dr. de Massy: For that, we need new tools. We have to develop new technologies or use technologies that have maybe been used for different purposes and design them for this particular system, which is mouse meiosis.

Lara Szewczak: What question would you ask first if you could pluck a new technology out of the air?

Dr. de Massy: I want to follow a specific DNA sequence as the meiosis is progressing, and to follow two sequences from two homologous chromosomes in the nucleus during the process of meiotic prophase. That would be a challenge.

Lara Szewczak: If you couldn't work on meiosis anymore, what would you work on? If somebody handed you a pile of money and said "Go do something new," what would you do?

Dr. de Massy: I would still get back to some evolutionary aspects. I've been thinking about two things. First, would be to reconstitute a molecular ancestry for the proteins we are studying now. That's one aspect. The other is similar, but in opposite direction. I would like to take cells and have them go for fifty thousand generations, to have a system for that. I know some people do that with bacteria because with the regeneration times of 20 minutes, you can do those. But I would like to have an evolution experiment to read the future. 


\section{$\$_{\text {CSH\& }}^{\infty}$ Cold Spring Harbor Symposia SYMPOSIA}

\section{A Conversation with Bernard de Massy}

Cold Spring Harb Symp Quant Biol 2017 82: 384-385 originally published online April 2, 2018 Access the most recent version at doi:10.1101/sqb.2017.82.034538

Creative This article is distributed under the terms of the

Commons http://creativecommons.org/licenses/by-nc/4.0/, which permits reuse and

License redistribution, except for commercial purposes, provided that the original author and source are credited.

Email Alerting Receive free email alerts when new articles cite this article - sign up in Service the box at the top right corner of the article or click here. 